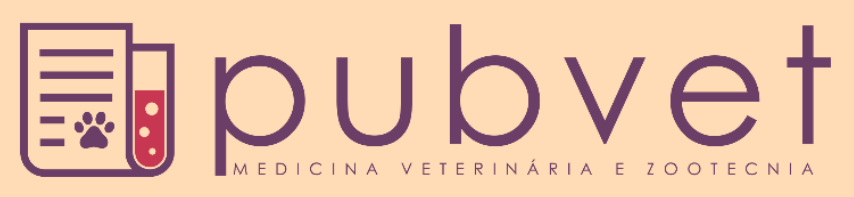

https://doi.org/10.31533/pubvet.v14n4a548.1-6

\title{
Displasia folicular dos pelos pretos em cães: Revisão
}

\author{
Adriana Leão de Carvalho Lima Gondim ${ }^{10}$, Adjanna Karla Leite Araujo ${ }^{2} \bullet$ \\ ${ }^{I}$ Médica veterinária graduada pela Universidade Federal Rural de Pernambuco - UFRPE, Pós-graduada em Dermatologia Veterinária de \\ Pequenos Animais pela instituição Qualittas - Universidade Castelo Branco. E-mail adrianalclg@ gmail.com \\ ${ }^{2}$ Médica veterinária graduada pela Universidade Federal de Campina Grande - Campus de Patos/PB, Pós-graduada em Dermatologia \\ Veterinária de Pequenos Animais pelas instituições Qualittas - Universidade Castelo Branco e Equalis, Especialização em Parasitologia \\ Clínica e Saúde Pública pela UPE, Mestrado em Ciências Veterinárias pela Universidade Estadual do Ceará e pelo Centro de Pesquisa Aggeu \\ Magalhães - FIOCRUZ-PE.E-mail: adjanna_leite@hotmail.com
}

Resumo. As doenças de peles são causas frequentes de atendimento na clínica de pequenos animais. A displasia folicular dos pêlos pretos é uma doença de origem hereditária cuja etiologia ainda não foi totalmente elucidada. Esta enfermidade afeta apenas a pelagem preta de cães jovens que apresentam pelagem bi ou tricolor. O diagnóstico é feito com base no histórico do paciente, exame clínico e exames complementares, como o tricograma e exame histopatológico. Por ser uma doença rara, esse artigo tem como objetivo reunir informações relevantes sobre a doença, alertando o médico veterinário sobre sua ocorrência.

Palavras chave: dermatologia, displasia, pelo preto, alopecia, cão

\section{Follicular dysplasia of black hair in dogs: Review}

\begin{abstract}
Skin diseases are frequent causes of veterinary care at the small animal clinic. Black hair follicular dysplasia is a disease of inherited origin whose etiology has not yet been fully elucidated. This disease only affects the black coat of young dogs that have bi or tricolor coat. The diagnosis is made based on the patient's history, clinical examination and complementary exams, such as trichogram and histopathological exam. Being a rare disease, this article aims to gather relevant information about the disease, alerting the veterinarian about its occurrence.
\end{abstract}

Keywords: dermatology, dysplasia, black hair, alopecia, dog

\section{Displasia folicular del pelo negro en perros: Revisión}

Resumen. Las enfermedades de la piel son causas frecuentes de atención veterinaria en la clínica de pequeños. La displasia folicular de los pelos negros es una enfermedad de origen hereditario cuya etiología aún no se ha aclarado por completo. Esta condición solo afecta el pelaje negro de los perros jóvenes que tienen pelaje bi o tricolor. El diagnóstico se realiza en función al histórico del paciente, el examen clínico y los exámenes complementarios, como el tricograma y el examen histopatológico. Al ser una enfermedad rara, este artículo tiene como objetivo recopilar información relevante sobre la enfermedad, alertando al veterinario sobre su aparición.

Palabras clave: dermatología, displasia, pelo negro, alopecia, perro

\section{Introdução}

A produção de melanina é geneticamente determinada e controlada por várias etapas enzimáticas, dando origem a uma grande variação nas cores da pele e do pêlo (Scott et al., 2001; Tatibana et al., 2012). As displasias foliculares são doenças de origem hereditárias causadas por anormalidades de 
melanização e anatômicas das unidades pilosebáceas (Cruz et al., 2015; Mecklenburg, 2006). As displasias foliculares ligadas à cor da pelagem são histopatologicamente e geneticamente semelhantes provavelmente tratadas da mesma forma; porém, apresentam-se clinicamente diferentes; enquanto a Alopecia por Diluição da Cor é observada de forma difusa, a Displasia Folicular dos Pelos Pretos (DFPP) é observada na forma localizada (Cruz et al., 2015; Ferreira et al., 2007; Mecklenburg, 2006; Miller et al., 2013). Essas afecções são também chamadas de displasias cutâneas neuroectodermais congênitas (Mecklenburg, 2006). Tem sido reportado que estas displasias apresentam folículos pilosos que não se desenvolvem após a fase telogênica, usualmente associados à intensa hiperqueratose no infundíbulo folicular, que pode ser causada por déficits de melanina (Cruz et al., 2015; Ferreira et al., 2007; Mecklenburg, 2006; Miller et al., 2013). A doença é caracterizada por perda focal ou generalizada de pelos pretos (Miller et al., 2013; Tatibana et al., 2012). A displasia folicular dos pelos pretos é considerada uma dermatopatia genética rara, constituindo no dia a dia da clínica veterinária, distúrbios patológicos pouco frequentes, não tendo, portanto, sua etiopatogenia bem elucidada (Arroyo \& Hincapié, 2018; Ferreira et al., 2007; Miller et al., 2013; Ríos et al., 1996).

Estudos indicam um problema primário no folículo piloso, envolvendo uma herança autossômica recessiva, o que leva a suspeita de uma produção defeituosa dos melanócitos sobre os folículos pilosos

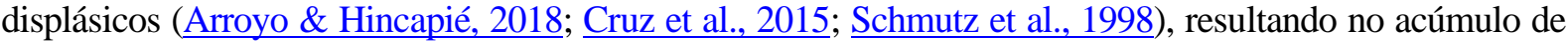
melanossomas em estágio IV nos bulbos foliculares e nos melanócitos da epiderme, com insuficiência na transferência de melanina para os queratinócitos adjacentes, muito similar à Síndrome de Griscelli em humano (Ferreira et al., 2007; Schmutz et al., 1998; Von Bomhard et al., 2006). Os pêlos com maior acúmulo de melanina acabam fragilizados, podendo ocorrer rupturas inclusive no interior do folículo piloso (Mecklenburg, 2006). Segundo Ferreira et al. (2007), estudos recentes levantaram a hipótese que a displasia folicular dos pelos pretos origina-se de um defeito ectodérmico, muito provavelmente ligado ao gene que codifica a melatonina (MLPH). Outra causa da doença foi atribuída a uma deficiência do hormônio estimulador da melanocitose, resultando na exposição das células do bulbo capilar a precursores tóxicos da melanina. Essa hipótese, no entanto, ainda não foi confirmada (Schmutz et al., 1998).

A doença acomete com mais frequência cães jovens, com pelagens bi ou tricolor (Ferreira et al., 2007), sendo uma delas de cor preta, esses animais nascem sem alteração na pelagem e vão se evidenciando mudanças como a perda do brilho da pelagem preta e perda progressiva do pelo nas áreas de pêlo preto (Arroyo-Munive et al., 2018; Ferreira et al., 2007; Gross et al., 2009; Paterson, 2010; Tatibana et al., 2012), começando a apresentar os sintomas por volta dos quatro meses de idade (Ferreira et al., 2007; Gross et al., 2009; Medleau et al., 2003; Paterson, 2010; Tatibana et al., 2012) até apresentar alopecia por volta dos seis a nove meses de idade, o que não ocorre nas áreas de pelagem branca (Arroyo-Munive et al., 2018; Cunha et al., 2005; Ferreira et al., 2007; Gross et al., 2009; Paterson, 2010; Tatibana et al., 2012). Não há predileção sexual (Paterson, 2010) e nem predisposição racial (Arroyo-Munive et al., 2018; Cunha et al., 2005; Schmutz et al., 1998), sendo descrito em cães mestiços e de raça puras, principalmente Basset Hound, Papilon, Cocker Spaniel Americano, Beagle, Dachshund, Yorkshire e Setter Gordon Pointer (Arroyo-Munive et al., 2018; Cunha et al., 2005; Ferreira et al., 2007; Gross et al., 2009; Paterson, 2010; Tatibana et al., 2012). Tatibana et al. (2012) relatam um caso de displasia folicular dos pelos pretos em um Terrier Brasileiro raça pura, popularmente conhecido com Fox Paulistinha.

Observa-se inicialmente o desbotamento dos pelos escuros que se tornam cinzas ou azulados principalmente na cabeça, orelhas, pescoço e tronco (Ferreira et al., 2007). As lesões são caracterizadas por alopecia ou hipotricose progressiva nas áreas de pelagem preta (Figura 1A). Também se pode observar descamação, pelos ressecados, opacos e quebradiços que se desprendem facilmente ao menor toque, contribuindo para as piodermities secundárias recorrentes nas áreas afetadas (Figura 1B), que podem provocar prurido (Arroyo-Munive et al., 2018; Cunha et al., 2005; Ferreira et al., 2007; Gross et al., 2009; Paterson, 2010; Tatibana et al., 2012). O tempo de evolução dos sintomas é variável (Paterson, 2010). 


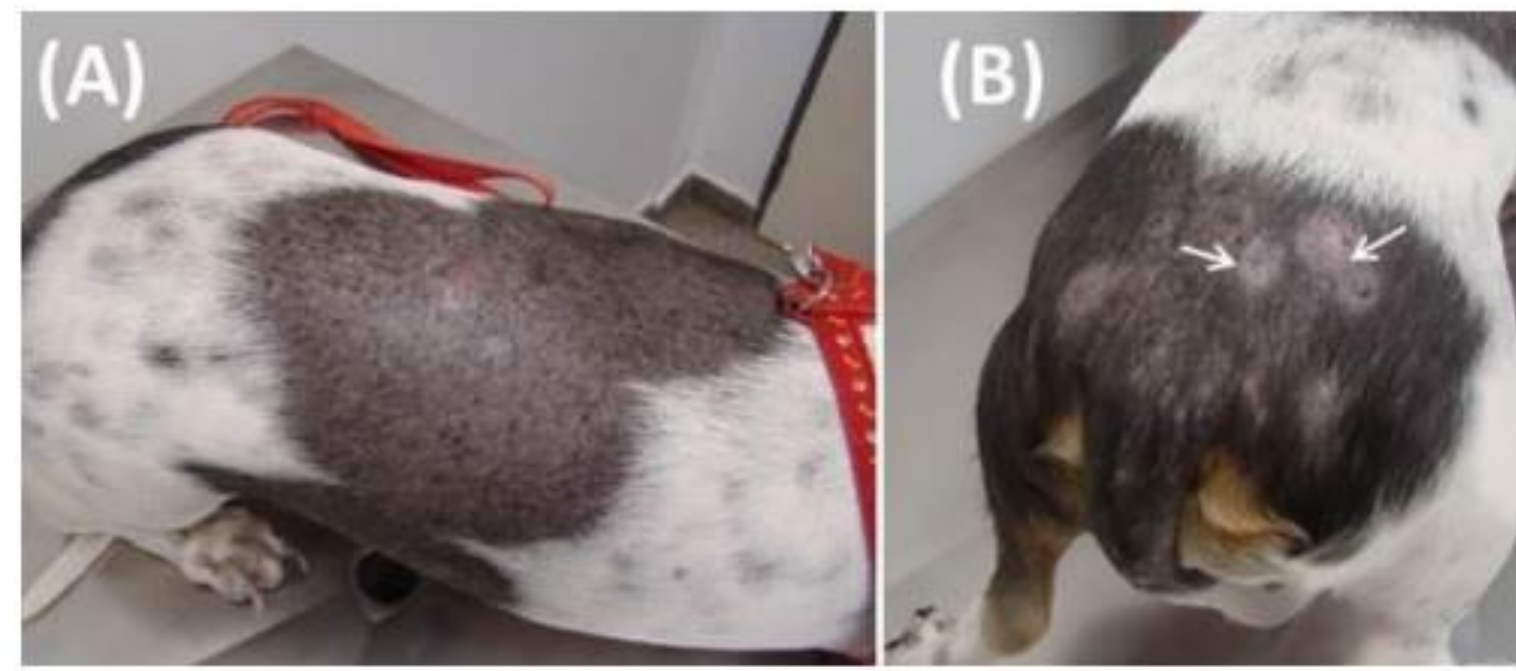

Figura 1. (A): Acentuada hipotricose em região de pelagem negra, com preservação das regiões de pelagem branca em cão diagnosticado com displasia folicular do pelo preto; (B): Colarinhos epidérmicos (setas) devido à piodermite secundária em paciente diagnosticado com displasia folicular do pelo preto. Fonte: Cruz et al. (2015)

\section{Diagnóstico e diagnóstico diferencial}

O diagnóstico da doença baseia-se no exame físico, histórico clínico, análise histopatológica das lesões cutâneas apresentadas pelo paciente e achados do tricograma (Cruz et al., 2015; Gross et al., 2009; Guaguère \& Bensignor, 2005; Paterson, 2010). Segundo Paterson (2010) a alopecia restrita às áreas de pelagem preta onde há redução ou ausência de hastes pilosas sugere o possível diagnóstico. As amostras devem ser colhidas das áreas onde a alopecia apresenta-se por completo ou das áreas indicativas da ocorrência de piodermite secundária (Gross et al., 2009; Paterson, 2010).

No tricograma, a arquitetura da haste pilosa apresenta-se alterada, dificultando a diferenciação entre medula, córtex e cutícula. A cutícula pode estar deformada, rompida ou mesmo ausente. Observa-se ainda acúmulos irregulares de melanina, denominados macromelanossomas (Figura 2), de tamanho e forma variável, nas regiões medular e cortical (Larson, 2016; Paterson, 2010).

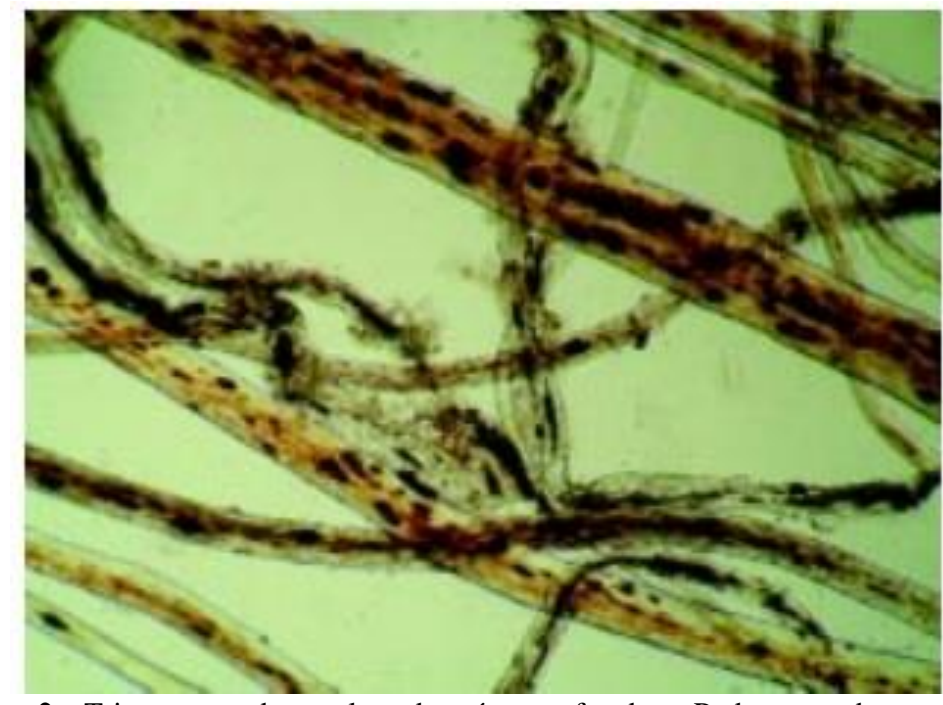

Figura 2. Tricograma dos pelos das áreas afetadas. Podem-se observar aglomerados irregulares de melanina na região cortical e medular, além de deformações do pelo. Fonte: Ferreira et al. (2007).

No exame histopatológico observa-se epiderme com epitélio estratificado plano com hiperqueratose ortoqueratótica epidérmica moderada e hiperacantose de intensidade variável. Diversos graus de displasia folicular, predominância de folículos pilosos inativos em fase telogênica, atrofia folicular além de múltiplos focos com pigmentação de melanina na camada basal e na lâmina própria normalmente são observados 
(Figura 2). No plano subepitelial, ocorre atrofia das glândulas sebáceas, folículos capilares dilatados, com presença de queratina em seu interior e no interior de macrófagos ao seu redor. As hastes dos pelos apresentam-se fraturadas com aglomeração de melanina livre. Pequenos focos de melanina também podem estar presentes no tecido adiposo adjacente (Arroyo \& Hincapié, 2018; Cardoso et al., 2003; Ferreira et al., 2007; Gross et al., 2009; Lopez et al., 2013; Miller, 1991; Paterson, 2010). Amostras de pele de áreas não pretas são normais (Gross et al., 2009; Medleau et al., 2003; Tatibana et al., 2012). O resultado do exame histopatológico da área afetada evidencia algumas características particulares da doença; porém, pode ser semelhante a outras displasias foliculares ou certas endocrinopatias que afetam a pele (Arroyo \& Hincapié, 2018; Ferreira et al., 2007), sendo o exame clínico e a minuciosa anamnese o que pode determinar o sucesso do diagnóstico (Arroyo \& Hincapié, 2018).

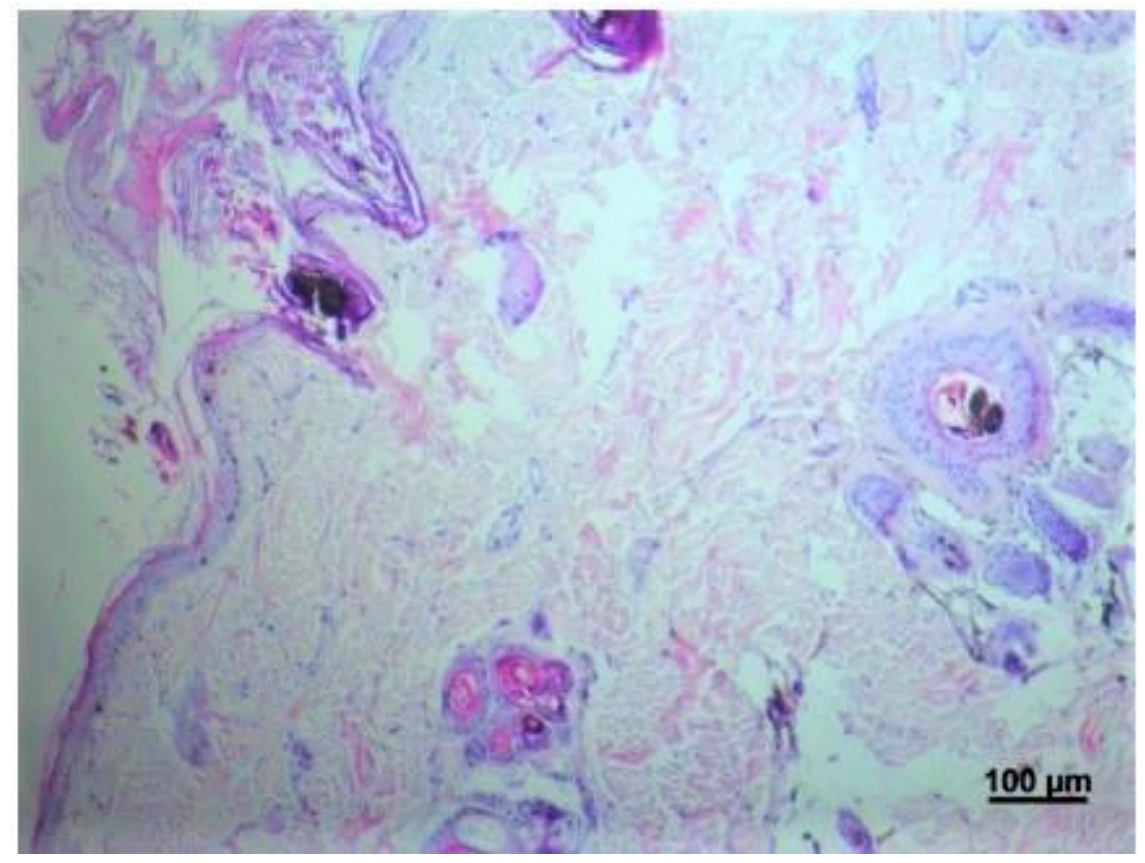

Figura 3. Pele, derme (HE, 10x). Exame histopatológico. Atrofia folicular acompanhada por acúmulo de melanina no interior e ao redor dos folículos pilosos. Fonte: Cruz et al. (2015).

O diagnóstico diferencial da DFPP inclui as demais displasias foliculares, principalmente a alopecia por diluição da cor, já que apresentam semelhanças histológicas e genéticas (Cunha et al., 2005; Ferreira et al., 2007). A democicose, piodermite superficial, dermatofitose e alopecias endócrinas são outros diagnósticos diferenciais (Medleau et al., 2003).

\section{Tratamentos}

Segundo Cunha et al. (2005) e Ferreira et al. (2007) não há tratamento efetivo para a displasia folicular dos pêlos pretos. A melatonina na dose de 3 a $6 \mathrm{mg} / \mathrm{animal}$ a cada 12 horas, tem sido utilizada como tentativa para a repilação dos animais portadores da enfermidade, com sucesso na reposição parcial dos pelos em aproximadamente $50 \%$ dos casos, embora seu modo de ação ainda seja desconhecido na doença (Cunha et al., 2005; Ferreira et al., 2007; Guaguère \& Bensignor, 2005).

Deve ser preconizado a utilização de shampoos antissépticos, cetomoduladores e emolientes durante toda a vida do paciente para controle das alterações de queratinização (Arroyo \& Hincapié, 2018; Ferreira et al., 2007; Gross et al., 2009). Pode-se ainda utilizar a suplementação com ácidos graxos essenciais, durante toda a vida do paciente para ajudar a manter e melhorar a camada de lipídios da pele e o aspecto do pelo apresentado pelo paciente (Ferreira et al., 2007). Terapia antimicrobiana deve ser realizada nos casos de piodermite secundária (Ferreira et al., 2007; Miller, 1991; Paterson, 2010).

\section{Prognóstico}

O prognóstico da doença é favorável, porém a alopecia é irreversível, dificultando a parte estética do animal, sem, no entanto, afetar sua saúde e qualidade de vida (Arroyo-Munive et al., 2018; Medleau et 
al., 2003; Palumbo et al., 2012). Os cães portadores da doença não devem ser reproduzidos, devendo, se possível, serem esterilizados, com o objetivo de prevenir a transmissão dos genes que causam o desenvolvimento da enfermidade, devido ao caráter hereditário da doença (Arroyo-Munive et al., 2018; Cunha et al., 2005; Medleau et al., 2003; Palumbo et al., 2012).

É de suma importância ter conhecimento de que algumas patologias que causam alteração da cor ou alopecia permanente, além de causar mudanças estéticas, podem levar a processos patológicos graves, como dermatite actínica e carcinomas (Arroyo \& Hincapié, 2018; Palumbo et al., 2012).

\section{Conclusão}

A displasia folicular dos pelos pretos é considerada uma doença dermatológica raramente observada na clínica de pequenos animais, devendo, porém, ser considerada como diagnóstico diferencial em casos de lesões alopécicas encontradas apenas nas áreas de pelagem pretas, principalmente de cães bi ou tricolores.

Deve-se sempre realizar um exame clínico minucioso em todo paciente com lesões na pele, observando atentamente seu histórico. Ressalta-se ainda a importância da realização de exames nesses pacientes. Para o correto diagnóstico da displasia folicular dos pelos pretos, além de anamnese minuciosa, é essencial a realização de tricograma para confirmação da doença, podendo-se ainda realizar exame histopatológico como exame complementar. Ainda não há tratamento efetivo para a afecção, devendo ser tratadas as doenças secundárias tais como defeitos da queratinização e piodermites recorrentes.

A doença normalmente afeta apenas a parte estética do paciente, não causando alterações em sua saúde e qualidade de vida, porém patologias que causam alteração da cor ou alopecia permanente podem levar a processos patológicos considerados graves.

Devido ao caráter hereditário, os cães portadores de displasia folicular dos pêlos pretos não devem reproduzir, devendo, quando serem possível, serem esterilizados.

\section{Referências Bibliográficas}

Arroyo, Y. J., \& Hincapié, L. C. (2018). Displasia folicular de la capa negra canina. Revista Colombiana de Ciencia Animal-RECIA, 10(2), 184-189.

Cardoso, M. J. L., Franco, S. R. V. S., \& Fabris, V. (2003). Displasia folicular em cão. Ciência Rural, 33(5), 949-951.

Cruz, T. P. P. S., Silva Machado, R. C., Cruz, F. A. C. S., Lima, S. R., \& Sousa, V. R. F. (2015). Displasia folicular do pelo preto em canino. Acta Veterinaria Brasilica, 9(3), 284-288.

Cunha, F. M., Silveira, L. M. G., Silva, P. T. D., Ferrigno, C. R. A., \& Futema, F. (2005). Displasia folicular dos pêlos negros: relato de caso. Clínica Veterinária, 59(10), 89-90.

Ferreira, R. R., Silva Machado, M. L., Aguiar, J., Spanamberg, A., Bianchi, S. P., Oliveira, E. C., \& Driemeier, D. (2007). Displasias foliculares ligadas à cor da pelagem em cães: displasia folicular dos pêlos pretos e alopecia por diluição da cor. Acta Scientiae Veterinariae, 35(1), 119-124.

Gross, T. L., Ihrke, P. J., Walder, J. E., \& Affolter, K. V. (2009). Doenças de pele do cão e do gato: diagnóstico clínico e histopatológico. Roca.

Guaguère, E., \& Bensignor, E. (2005). Terapêutica dermatológica do cão (Vol. 1). Roca.

Larson, C. E. (2016). Tricologia. In C. E. Larson \& R. Lucas (Eds.), Tratado de medicina externa: dermatologia veterinária. Interbook.

Lopez, T. V., Schons, S. V., Nobre, M., Tortato Vieira, N., Souza, P., \& Glomba, G. S. (2013). Displasia flicular do pêlo preto em canino. Archives of Veterinary Science, 18(3), 606-608.

Mecklenburg, L. (2006). An overview on congenital alopecia in domestic animals. Veterinary Dermatology, 17(6), 393-410.

Medleau, L., Hnilica, K. A., \& Fagliari, G. S. (2003). Dermatologia de pequenos animais: atlas colorido e guia terapêutico. Roca.

Miller, W H. (1991). Alopecia associated with coat color dilution in two Yorkshire terriers, one saluki, 
and one mix-breed dog. The Journal of the American Animal Hospital Association (USA), 27, 3943.

Miller, William Howard, Griffin, C. E., Campbell, K. L., \& Muller, G. H. (2013). Muller and Kirk's Small Animal Dermatology. Elsevier Health Sciences.

Palumbo, M. I. P. A., Fabris, V. E., \& Machado, L. H. A. (2012). Carcinoma de células escamosas em um cão com alopecia por diluição de cor. Veterinária e Zootecnia, 19, 507-512.

Paterson, S. (2010). Manual de doenças da pele do cão e do gato. Guanabara Koogan.

Ríos, A., Fernández, T., \& Gómez, L. (1996). Displasia folicular en un Doberman adulto de capa negra: un caso clínico. Clínica Veterinaria de Pequeños Animales, 16(1), 40-44.

Schmutz, S. M., Moker, J. S., Clark, E. G., \& Shewfelt, R. (1998). Black hair follicular dysplasia, an autosomal recessive condition in dogs. The Canadian Veterinary Journal, 39(10), 644-646.

Scott, D. W., H., M. W., \& E., G. C. (2001). Mullerand Kirk's small animal dermatology. WB. Saunders.

Tatibana, Lílian Sayuri, Paglioni, D. N., \& Costa Val, A. P. (2012). Black hair follicular dysplasia in a Brazilian Terrier: a case report. Revista Brasileira de Ciência Veterinária, 19(1), 3-6.

Von Bomhard, W., Mauldin, E. A., Schmutz, S. M., Leeb, T., \& Casal, M. L. (2006). Black hair follicular dysplasia in Large Münsterländer dogs: clinical, histological and ultrastructural features. Veterinary Dermatology, 17(3), 182-188.

Recebido: 21 de novembro, 2019.

Aprovado: 21 de dezembro, 2019.

Publicado: 15 maio 2020 .

Licenciamento: Este artigo é publicado na modalidade Acesso Aberto sob a licença Creative Commons Atribuição 4.0 (CC-BY 4.0), a qual permite uso irrestrito, distribuição, reprodução em qualquer meio, desde que o autor e a fonte sejam devidamente creditados. 